\title{
Two Internal Critiques for Theists Who Oppose Moral Enhancement on a Process Virtue Basis
}

\author{
Abe Brummett and Parker Crutchfield
}

\section{Introduction:}

Some bioconservatives reject the use of biotechnology for moral enhancement while simultaneously purporting to accept standard theism and process virtue (STPV). Standard theism holds that God is a personal, omniscient, omnibenevolent, omnipotent, transcendent being (Peterson 2013, 10). ${ }^{\text {i }}$ Process virtue holds that intrinsically valuable virtue can only be obtained through a specific process and not by means of biotechnological shortcuts. For example, proponents of the view may claim that the virtue of compassion cannot be achieved by taking a pill but must come about from organic life experience that involves struggle, suffering, and reflection. We describe two internal critiques, one conceptual and the other moral, that arise by combining standard theism and process virtue to reject moral enhancement. First, the conceptual critique argues there is an inconsistency that arises when the process virtue view is applied to the concept of God himself. STPV inconsistently holds that intrinsically valuable virtue must arise through a process, yet also posits the existence of an immutable, omnibenevolent God, whose intrinsically valuable virtue never arose through a process. Theistic bioconservatives must either give up the notion that God has always been perfectly virtuous or give up their claim that virtue must be obtained through a particular kind of process. Second, the moral critique argues that rejecting moral enhancement on a process virtue basis is selfish, which is held to be a vice on all mainstream manifestations of standard theism (e.g., Christianity, Judaism, Islam). Process virtue is selfish because it requires prioritizing the intrinsic value of developing one's own virtue through a process over using moral enhancement that will improve one's ability to help others. We conclude that the combination of standard theism and process virtue does not serve as a strong basis from which to oppose moral enhancement.

\section{Moral Enhancement:}

There are a variety of methods of moral enhancement, which is the practice of improving moral capacities relative to a person's baseline moral capacities. Education is the most traditional form of enhancement, but there are others. We are interested only in the non-traditional forms of moral enhancement, those that occur by biotechnological means. These methods of enhancement typically entail the administration of some biological agent, such as oxytocin or psilocybin, which may promote pro-social behaviors. Both agents seem to make people more empathetic, at 
least in some circumstances (De Dreu 2011; De Dreu 2016; Pokorny 2017; Timmermann 2017). This category of non-traditional biological enhancement may also include interventions that don't target moral capacities directly. Interventions that target cognitive capacities may improve moral reasoning and thus moral behavior (Douglas 2008; Persson 2008). Or interventions may use classical conditioning to improve moral capacities, such as an intervention that induces vomiting any time one is motivated to hurt another person. These are the kinds of interventions we are interested in, and to which the proponent of objects STPV.

\section{The Standard Theistic Process Virtue Critique of Moral Enhancement:}

Theistic bioconservatives view moral enhancement as embodying an objectionable attitude towards the mastery of human nature. The 2003 President's Commission calls this "hyperagency," a "Promethean aspiration to remake nature, including human nature, to serve our purposes and to satisfy our desires" (Kass 2003, 288). To check this hyper-agency, bioconservatives appeal to the "giftedness" of the world to instill a sense of humility such that we stop seeing the world - including ourselves - as open for use and modification in any way we desire. Recognizing the world as gifted means acknowledging that "our talents and powers are not wholly our own doing, nor even fully ours, despite the efforts we expend to develop and to exercise them" (Kass 2003, 288). It is claimed that a respect for giftedness instills a healthy sense of stewardship towards being rather than what Kass calls the worrisome talk of "our bodies and minds - or human nature itself — as if they were mere raw material to be molded according to human will" (Kass 2003, 289). With this notion of giftedness, bioconservatives are appealing to modesty, humility, and restraint in the presence of those who think themselves wise enough to enhance human nature. For theistic bioconservatives, the giftedness of human nature and morality implies a giver, and aspects of our nature that have been gifted to us by a God are inherently sacred and not to be tampered with. Leon Kass epitomizes this view when he writes, "Will man remain a creature made in the image of God, aspiring to align himself with the divine, or will he become an artifact created by man in the image of God-knows-what, fulfilling the aspirations only of human will?" (Flaumenhaft 2003). ${ }^{\text {ii }}$

Although bioconservatives appeal to the giftedness of nature, Kass is careful to note that not everything gifted by nature is to be valued. He writes, "the giftedness of nature also includes smallpox and malaria, cancer and Alzheimer disease, decline and decay" (Kass 2015, 20). Instead of a generalized appreciation for the giftedness of all nature, Kass advocates for a special admiration for the gift of our own human nature (Kass 2015, 21). Kass is calling for us to recognize something "inherently good or dignified" about,

$[\mathrm{N}]$ atural procreation, human finitude, the human life cycle, the human erotic longing and striving. Only if there is something inherently good or dignified about the ways in which we engage the world as spectators and appreciators, teachers and learners, leaders and followers, agents and bakers, lovers and friends, parents and children, and as seekers of our own special excellence and flourishing, in whatever areas to which we are called, only then can we begin to see why those aspects of nature need to be defended (Kass 2015, 21-22).

By calling that we "pursue our own special excellence," Kass is not making a transhumanist claim. He believes such pursuits must never go so far as to make us something more than human, 
Penultimate draft. Please cite the final draft to appear in Bioethics.

writing, "To turn a man into a cockroach would be dehumanizing. To try to turn him into more than a man might be so as well" (Kass 2015, 21).

Part of recognizing the giftedness of human nature is respecting the process by which virtue must be achieved. Process virtue claims that if humans are allowed to "cheat" their way to being "moral" then they will only cheat themselves, as it is not possible to take biotechnological shortcuts to achieve true virtue. Kass writes, "A drug to induce fearlessness does not produce courage" (Kass 2015, 24). Virtues can only be obtained through a process involving hard work, striving, struggling, and resilience in the face of failure. Human enhancement would allow achievements to come too easily, which would cheapen the sense of accomplishment and erode the virtues normally developed through a process. In Beyond Therapy, the President's Council notes that, "Many people believe that each person should work hard for his achievements [...] This matter of character - the merit of disciplined and dedicated striving — is surely pertinent" (Kass 2003, 291). In short, without suffering, we would have no saints.

The idea that virtue must be born of a process has its contemporary theological roots in the soulbuilding theodicy of John Hick with even deeper roots in the writings of St. Irenaeus. Soulbuilding theodicy is a competing solution to Augustinian theodicy. Augustinian theodicy argues that God creates only good things, and that evil entered the world when humanity became flawed through sin. Alternatively, soul-building theodicy begins by asking why God may have preferred to create imperfect, developing creatures rather than morally perfect beings from the outset (Hick 2010, 319). Soul-building theodicy answers this question by seeing true virtue as the result of a process wherein an imperfect being with "genuine freedom" comes to freely choose the good in the right kind of environment. The right kind of environment is one of scarcity, uncertainty, stress, and temptation that gives humans many opportunities to do truly good actions, opportunities not afforded in a "morally frictionless" environment (Peterson 2013, 196-7). A morally frictionless environment is one where all our needs are met, and character is not given a chance to develop. On Hick's view, we must begin as imperfect beings and earn our virtue through freely choosing to be good while living in a contingent, unpredictable world where we do not know how things will turn out. Such a world gives us the chance to develop true virtue, to sacrifice for one another, to really love. Hick extolls the value of process virtue by appealing to the "principle that virtues which have been formed within the agent as a hard-won deposit of her own right decisions in situations of challenge and temptation, are intrinsically more valuable than virtues created within her ready-made and without any effort on her own part" (Hick 2010, 320, emphasis added). This belief in the intrinsically valuable nature of hard-won character sits at the heart of the argument for process virtue and against the use of biotechnology for moral enhancement. On the process virtue view, there is no shortcut to intrinsically valuable virtue hard won in the contingencies of suffering and uncertainty; God could not have simply created perfectly virtuous beings, they had to be forged through a process. So too would virtue acquired through biotechnology be similarly deficient, another way of trying to create a shortcut to genuine virtue that can only be acquired through the right kind of process. Virtue must be earned, not biotechnologically "enhanced." 


\section{The Internal Conceptual Critique-God's Virtue Did Not Arise from A}

\section{Process:}

While the combination of standard theism and process virtue (STPV) may appear to initially present a strong challenge to moral enhancement, we now turn to raising two internal critiques of the view. One critique arises by applying the claim of process virtue to standard theism itself. Problematically, STPV claims that virtue gained by free choice in the right sort of process is intrinsically more valuable than ready-made virtue, yet also posits the existence of a being with perfect virtue (God), whose virtue was not developed through a process. For those who claim standard theism, there was never a time when God's virtue was less than perfect, it never had to be "hard-won" through an environment full of moral friction. For those who accept standard theism, it cannot be the case that virtue must arise through a process while simultaneously holding that the exemplar of virtue - God — did not develop his virtue through a process. The positing of such a being directly contradicts the claim at the heart of the process virtue view, which asserts there is a process that must be followed if real, intrinsically valuable virtue is to result. A theistic proponent of process virtue must either revise their view of God to say that he too must have developed his virtue through a process or accept that process is not a necessary component of developing virtue.

One likely response is to argue that while process is not logically necessary for virtue (because God did not need a process), it is necessary for temporal, finite creatures like us. In other words, an antecedent can be added to the process virtue account to read: If the virtue of temporal, finite creatures develops as a result of a process, then following this process is the only way to achieve genuine virtue and therefore moral enhancement, which attempts to shortcut this process, should be rejected. ${ }^{\text {iii }}$ We can say this response draws a distinction between finite, temporal, earthly virtue vs infinite, atemporal, divine virtue - noting that the former must develop virtue through a process but the latter does not. The trouble with this response is that such a distinction cannot be simply asserted, it must be explained; an account is needed for why an omnipotent, omnibenevolent, omniscient God should choose to create temporal, finite creatures like us whose virtue can only be formed through a certain kind of process, and not creatures whose virtue could have been fully actualized without a process. After all, many proponents of theism and process virtue also hold that humans were created in God's image, so an explanation of why humans are so unlike God with regards to virtue development is needed.

The explanation commonly given by proponents of STPV here is that God should want to create creatures like us because process virtue is of greater intrinsic value than ready-made virtue. Of course, such an explanation again runs in direct contradiction with the idea of a being with perfect virtue that is of infinite intrinsic value and never arose through a process. The attempt to escape the dilemma by differentiating between divine virtue (that does not require a process) and earthly virtue (that requires a process) will be unsuccessful, because any explanation must contend with the fact that God could have made any logically possible world. If it is logically possible for intrinsically valuable virtue to exist without a process (which the standard theist must admit) then the existence of a world designed for the explicit purpose of creating intrinsically valuable virtue becomes unexplainable. It seems that STPV cannot maintain a distinction between process earthly virtue and ready-made divine virtue. Virtue either does, or does not, require a process to be intrinsically valuable, but STPV has tried to have it both ways. 
Even if the distinction between virtue for creatures like us vs divine virtue could be plausibly maintained (which we have argued it cannot), there are consequences a proponent of STPV will be unlikely to accept. STPV holds that process virtue is necessary for creatures like us, which presumably means humans specifically. If the creatures like us response has specifically humans in mind, then, by definition the process virtue view does not hold for creatures unlike us. There are a variety of ways we might metaphysically differentiate beings like us from beings unlike us. One way to do so is by moral status (DeGrazia 2012). We would not expect the necessity relation between virtue and process to obtain for beings with a lower moral status, such as a chimpanzee or pig. Similarly, we should not expect the necessity relation between virtue and process to obtain for beings with a higher moral status. For beings with a higher moral status - creatures unlike us - it is not necessary for virtues to develop through a process. Here is one way that one might become virtuous in the absence of a process: genetic enhancement of a sperm or egg, leading to an individual with a higher moral status, a transhuman, or a moral post-person (Douglas 2013; Agar 2013). There is nothing in the "creatures like us" claim that precludes using CRISPR or some other germline editing technique to create creatures unlike us, e.g. transhumans, or moral post-persons. After all, interventions on a sperm or egg are interventions on things that have no moral status. And at whatever point a person results from the "enhanced" gamete (either upon the creation of an embryo or upon birth), the person is a being unlike us. Instead, it is a transhuman with superior virtues or moral capacities. At no point in the creation of the being was the alleged necessity relation between process and virtue violated, because that relation doesn't hold for creatures unlike us. Thus, the theistic bioconservative who objects to interventions like moral bioenhancement on process virtue grounds has no reason to object to these interventions. To prevent the consequence that it would be morally permissible to use germline editing to create persons unlike us (e.g., transhumans), proponents of STPV will need to carefully qualify the metaphysical boundaries of what it means to be a "creature like us."

In summary, internal problems arise when applying process virtue to standard theism. It is difficult to see how STPV can be rendered consistent given that the exemplar of virtue (God) sits as the antithesis to process virtue. Additionally, insisting that process virtue only applies to "creatures like us" draws a distinction between earthly and heavenly virtue that will be difficult to maintain, and, even if it could be maintained, has implications a proponent of STPV will be unlikely to accept, namely, that STPV may only prohibit moral enhancement for creatures like us but not for creatures unlike us, e.g., posthumans.

\section{The Internal Moral Critique-The Selfishness of Process Virtue:}

On STPV, it is not any process (after all, the daily act of taking a moral enhancing pill is a process), but the right kind of process that is needed for developing virtue, a process that involves a lifetime of contingency, struggle, failure, resilience, etc. However, a second internal critique of STPV arises by observing that, by their own lights, there are good reasons to consider one who chooses process virtue over live moral enhancement alternatives to be an extraordinarily selfish individual.

Suppose that one is considering taking a pill that "enhances" their cognition, and thus their moral reasoning, motivation, and behavior, whatever this amounts to. Prior to taking the pill, the person is an ordinary imperfect moral agent. He does some good things and some bad things and is subject to the same sort of cognitive biases that afflict us all. His moral motivations sometimes 
align with his moral judgments, but often he lacks the discipline to maintain good behaviors. He is motivated to be a better person, however. Before him are two options. One option is that he can take the pill and over a very short period be able to make better moral judgments and be more motivated to act on them, which results in him exhibiting more moral behavior. The second option is to forgo the pill and engage in a long, difficult process, one that may take years to achieve the same moral judgments, motivations, and behavior as he would have had much sooner by taking the pill. But even then, his success is not guaranteed.

Proponents of STPV object to taking a moral enhancement pill because it requires the person to sacrifice the intrinsic value of the virtue that results. But this sacrifice is for an aim that proponents of STPV consider to be a very high, perhaps the highest, moral aim-improving the lives of others. Moral enhancement may be used as shortcuts to personal virtues (e.g., courage, temperance, resilience), but improvement of personal virtue is often not the primary aim of these moral enhancements. The primary aim of moral enhancement is to improve the lives of others by preventing the widespread suffering associated with climate change, the proliferation of weapons of mass destruction, pandemic, or any other collective risk (Douglas 2008; Persson 2008; Persson and Savulescu 2012; Savulescu and Persson 2012). Relative to the goal of acquiring personal virtues, taking a moral enhancement, according to proponents of STPV, is an inappropriate shortcut. But relative to the goal of helping others, taking a shortcut, especially one that requires the person to freely sacrifice some of the development of their own personal virtue, would seem like a laudable aim, especially given the high value often ascribed to other-regarding behavior by traditional forms of standard theism. Such a sacrifice is not a one-time sacrifice. So long as the moral enhancement is effective, according to STPV, one is sacrificing their own virtuous self-improvement for the sake of the others - he cannot virtuously self-improve while the pill is working. Every day, he wakes up and takes his pill, thinking to himself that he is sacrificing his own virtuous self-improvement so that he is able to get off the couch and go to the food pantry.

The proponent of process virtue objects to moral enhancement on the grounds that it is an inappropriate shortcut to building virtue. Combining this claim with the claim that moral enhancement prevents others' suffering implies that it is more valuable to virtuously selfimprove than it is to prevent others' suffering. An adaptation of Peter Singer's famous thought experiment can help make the shortcoming of this view even more vivid (Singer 1972). Suppose a child is drowning in a shallow pond, and the proponent of process virtue is the only person in a position to save the child. Before her are two paths, one is a direct and easy path leading to the pond. The other is a long, winding path with many obstacles that will significantly improve the person who overcomes them. The proponent of process virtue, in objecting to moral enhancement, is committed to the claim that it is better to take the long, winding, obstacle-ridden path. But she is also committed to the claim that it is better to do so, even if the child dies as a result of forgoing the shortcut to the pond. After taking the virtuous path and finding the child dead, the proponent of process virtue emerges from the difficult but self-improving path, looks at the grief-stricken parents, and says, "It's better this way. Although your child died, I've become a better person." This is the view that the proponent of process virtue is committed to. It is an implausible commitment. Worse, it is extremely selfish and callous. One would be rightly skeptical of the person who justified their actions that it was permissible to allow the child to drown for the sake of their own self-improvement. ${ }^{\text {iv }}$ 
The proponent of STPV who objects to moral enhancement is committed to an implausible view, but it is also incoherent given her other moral commitments. Forgoing suffering-preventing moral enhancement for the sake of virtuous self-improvement is extremely selfish. Participating in such extreme selfishness is also vicious because it undermines the pursuit of other-regarding virtues. Extreme selfishness is incompatible with the moral commitments of all mainstream versions of standard theism, such as Judeo-Christian morality. Judeo-Christian morality holds that human flourishing involves promoting the well-being of others, not in selfishness. Thus, the proponent of STPV betrays her own religious moral foundations. According to proponents of STPV, promoting others' well-being is good, and promoting others' well-being while sacrificing one's own well-being is even better. Therefore, by their own lights, proponents of STPV have good reasons to endorse moral enhancement.

One might think that we are holding the proponent of STPV to a claim that they do not, and need not, hold. The proponent of STPV is committed to the claim that, ceteris paribus, the long, selfish, virtue-developing path is more valuable than the short, other-regarding path. But things aren't often equal, and the proponent of the STPV might protest that we are imposing upon them a position that they don't hold: that the longer selfish path is all things considered more valuable. STPV, according to this objection, does not imply that the longer selfish path is all things considered more valuable. Thus, when ceteris is not paribus she can claim that the shortcut is more valuable.

The problem with this objection is that, if true, the value secured in taking the shortcut and preventing others' suffering easily overwhelms STPV. If the value secured by taking the shortcut (e.g., saving the child, preventing the suffering associated with collective risks) can override whatever value is secured by taking the longer self-regarding path, then it is compatible with STPV for a person to take the shortcut to being a better person - to being enhanced - so long as the value achieved in doing so is greater than the value in not. But this imperative - take the path that secures the most value - is garden-variety consequentialism. If the proponent of STPV wants to block this collapse into consequentialism, then she needs to hold that STPV does entail that the longer selfish path is, all things considered, better than the shorter other-regarding path, regardless of the consequences of taking the shortcut.

The proponent of STPV may fall back at this point and claim that taking the long, self-regarding path is more intrinsically valuable than taking the shortcut. Since it is more intrinsically valuable, the longer path is the better path. This objection fails to save her position. Claiming that the long path is more intrinsically valuable than the shortcut assumes either that (a) preventing others' suffering is not intrinsically valuable or (b) preventing others' suffering is intrinsically valuable, but just less so than improving oneself. If anything is intrinsically valuable, however, preventing others' suffering would seem to be intrinsically valuable. Holding (a) and denying that preventing others' suffering is intrinsically valuable effectively illuminates the core selfishness of the STPV - it's not others' suffering that matters, but one's developed virtues. The parents of the drowned child might likewise disagree when the proponent of STPV emerges from the long path and tells them that saving their child wasn't intrinsically valuable.

Holding (b) and allowing that preventing others' suffering is intrinsically valuable, just less so than developing one's virtue, also doesn't help the proponent of STPV. When the proponent of STPV chooses the longer route, they do so to pursue something they believe to be of greater intrinsic value (their process virtue). But this choice overlooks the intrinsic value that shorter 
route secures, namely, the reduction in harm and suffering of others. The proponent of STPV must choose the intrinsic value of developed virtue over the intrinsic value of reduced harm, and in selecting the former, STPV makes a self-regarding choice that is morally inconsistent with the other-regarding moral framework of their own view. One should question the quality of the character of the person who emerges from the long path and stands (in the shallow water) at the feet of the young corpse and claims virtue. But according to the proponent of STPV, that's who we should all aim to be. Given the Judeo-Christian roots of STPV, this result reveals the internal incoherence of the view.

The problem for the proponent of STPV is that the view becomes implausible and incoherent when it is conjoined with the empirical claim that moral enhancement prevents the suffering of others. They can avoid the problem of selfishness by rejecting the foundations of their view (e.g., that selfishness is wrong), abandoning their objection to enhancement, or by denying that enhancement prevents suffering. To preserve their view, the proponent of STPV will take the third option and deny that enhancement prevents others' suffering. The claim that enhancement prevents others' suffering is a descriptive claim, not a normative one. It is something that can only be rejected or confirmed empirically. Denying it on normative grounds gets the metaphysical relation between facts and values all wrong. Values supervene on facts, or the normative supervenes on the descriptive. Denying the descriptive on normative grounds is to attempt to construct the descriptive domain out of what one thinks that domain should be, rather than on what is observed. While it may be true that all observation is value-laden, those who hold that how things are is a function of how things should be are mistaken.

The proponent of STPV might instead attempt to accommodate the notion that enhancement prevents suffering by admitting as much but claiming that in doing so the enhanced sacrifice their individual freedom, which is of greater value than the prevention of others' suffering. This objection really is the conjunction of two claims. The first is the metaphysical claim that being enhanced requires the sacrifice of freedom. The second is that sacrificing individual freedom is worse than allowing preventable suffering to occur. Both claims have been extensively adjudicated in the literature. The result of this adjudication, we believe, is that both claims are false. The proponent of STPV will not accept this adjudication, however, at least as it pertains to the second claim. Accepting that allowing preventable suffering is worse than sacrificing freedom saps the proponent of STPV of resources to respond to one of the most challenging arguments against standard theism, the Problem of Evil, and thus threatens the foundations of their view. But for this strategy to resolve their present problem, both claims need to be true, and the metaphysical claim is false: being enhanced does not require the sacrifice of freedom. We have little to add to the debate regarding this claim, which seems to have been settled sometime in the late 2010s (Harris 2011; Savulescu and Persson 2012; Pugh 2019). One idea that this debate sometimes skips over, however, is that if enhancement requires the sacrifice of freedom, then humans never really had freedom in the first place. As we learn more about the brain and mind, it is clear that factors external to the person strongly influence one's judgments and subsequent behavior. Most of these factors are beyond an individual's control. This influence is not new, though our knowledge of it may be. There is no reason to think that the causal relations that obtain between an enhancement and the resulting judgment undermine freedom any more or less than any of the causal relations that obtain between the frequent ordinary influences and the resulting judgments. So, unless the proponent of STPV can motivate the claim that enhancement 
Penultimate draft. Please cite the final draft to appear in Bioethics.

entails some special metaphysics, resolving their problem of selfishness by claiming that enhancement requires sacrificing freedom is not going to work.

\section{Conclusion:}

We have articulated two internal critiques that proponents of STPV who oppose moral enhancement must address if they wish to preserve the integrity of their view. Importantly, our argument does not show there are no good reasons to oppose moral enhancement. There may be good reasons, and the proponent of STPV may even be able issue them. But those reasons, whatever they may be, won't be grounded in the conjunction of standard theism and process virtue. There is no space for a person to assert standard theism and process virtue and to also reject moral enhancement on those grounds. Thus, the proponent of STPV can choose between one of three options: reject standard theism, reject process virtue, or find a way to make the endorsement of moral enhancement compatible with her other intellectual commitments.

\section{References:}

Agar, Nicholas. 2013. "Why is it possible to enhance moral status and why doing so is wrong?" Journal of Medical Ethics 39 (2):67-74.

De Dreu, C.K.W., Greer, L.L., Van Kleef, G.A., Shalvi, S., \& Handgraff, M.J.J. 2011. "Oxytocin promotes human ethnocentrism." Proceedings of the National Academy of Sciences 108 (4):1262-1266.

De Dreu, Carsten KW, and Mariska E. Kret. 2016. "Oxytocin conditions intergroup relations through upregulated in-group empathy, cooperation, conformity, and defense." Biological psychiatry 79 (3): 165-173.

DeGrazia, David. 2012. "Genetic enhancement, post-persons and moral status: A reply to Buchanan." Journal of Medical Ethics 38 (3):135-139.

Douglas, Thomas. 2008. "Moral enhancement." 25 3:228-245.

Douglas, Thomas. 2013. "Human enhancement and supra-personal moral status." Philosophical Studies $162(3): 473-497$.

Flaumenhaft, Harvey. 2003. "The Career of Leon Kass." J. Contemp. Health L. \& Pol'y 20:v.

Harris, John. 2011. "Moral enhancement and freedom." Bioethics 25 (2):102-111.

Hick, John. 2010. "Soul-Making Theodicy." In Philosophy of Religion: Selected Readings, edited by William Hasker Michael Peterson, Bruce Reichenbach, David Basinger. New York: Oxford University Press.

Kass, Leon. 2003. Beyond therapy : biotechnology and the pursuit of happiness: Washington, D.C. : President's Council on Bioethics, [2003]. Bibliographies.

Kass, Leon R. 2015. Raymond Waggoner Lectures - Leon R. Kass, Ageless Bodies, Happy Souls: Biotechnology and the Pursuit of Perfection, 2003. 2014.

Persson, Ingmar, and Julian Savulescu. 2008. "The perils of cognitive enhancement and the urgent imperative to enhance the moral character of humanity." Journal of applied philosophy 25 (3):162-177.

Persson, Ingmar, and Julian Savulescu. 2012. Unfit for the future : the need for moral enhancement, Uehiro series in practical ethics: Oxford : Oxford University Press, 2012.

Peterson, Michael L. 2013. Reason and religious belief : an introduction to the philosophy of religion: New York : Oxford University Press, [2013] 5th ed. 
Penultimate draft. Please cite the final draft to appear in Bioethics.

Pokorny, T., Preller, K.H., Kometer, M., Dziobek, I., \& Vollenweider, F.X. 2017. "Effect of psilocybin on empathy and moral decision-making." International Journal of Neuropsychopharmacology 20 (9):747-757.

Pugh, Jonathan. 2019. "Moral Bio-enhancement, Freedom, Value and the Parity Principle." Topoi 38 (1):73-86.

Savulescu, Julian, and Ingmar Persson. 2012. "Moral Enhancement, Freedom, and the God Machine." Monist 95 (3):399.

Singer, Peter. 1972. "Famine, Affluence, and Morality." Philosophy \& Public Affairs 1 (3):229-243.

Timmermann, M., Jeung, H., Schmitt, R., Boll, S., Freitag, C.M., Bertsch, K., \& Herpertz, S.C. 2017. "Oxytocin improves facial emotion recognition in young adults with antisocial personality disorder." Psychoneuroendocrinology 85:158-164.

\footnotetext{
'The key attribute focused on in this paper is God's omnibenevolence, which Peterson et al define as being "perfectly morally good. Whatever character traits, principles of action, and so on it may take to qualify as a being as morally perfect" (Peterson 2013, 147).

ii Harvey Flaumenhaft quotes these remarks of Leon Kass from October of 2001, when Kass received an honorary doctorate from the Spertus Institute of Jewish Studies.

iii We thank an anonymous reviewer for raising this objection.

iv Equally implausibly, the proponent of STPV must hold that developing other-regarding virtues by taking the long, selfish, self-improving path is better than actually regarding others in one's behavior.
} 